\title{
Calculation Accuracy and Efficiency of a Transient Model for Submerged Entry Nozzle Clogging
}

\author{
H. BARATI, M. WU, A. KHARICHA, and A. LUDWIG
}

A transient numerical model was proposed and validated by the current authors for nozzle clogging (Barati et al. in Powder Technol 329:181-98, 2018). The model can reproduce the experiment in pilot scale satisfactorily. In the present article, the main objective is to validate the model for application in industry process continuous casting of steel, referring to the model accuracy and calculation efficiency. The results have shown that for the complex geometry of submerged entry nozzle (SEN), where it is difficult to create hexahedron mesh in the entire domain, a mixed mesh type is recommended, i.e., the wedge mesh for regions adjacent to SEN walls and the tetrahedron mesh for inner regions. Another challenge to the calculation of real SEN clogging is the huge number of particles involved in the industry process. An artificial factor, the $\mathrm{N}$-factor, has to be introduced to reduce the calculation cost. A dimensionless number $(\alpha)$ is defined to limit the $\mathrm{N}$-factor and ensure the modeling accuracy. Simulation of a test case has indicated that by an appropriate $\mathrm{N}$-factor (1000, corresponding to $\alpha=6 \times 10^{-5}$ ), the calculation time would be reduced significantly to a reasonable time.

https://doi.org/10.1007/s11663-019-01551-x

(C) The Author(s) 2019

\section{INTRODUCTION}

NozZLE clogging describes a phenomenon of the blockage of the flow passage, which is due to a gradual buildup of solid materials on the nozzle wall. This buildup of solid materials would disturb the fluid flow in the passage before the blockage. During the continuous casting of steel, clogging of the submerged entry nozzle (SEN) is a long-term problem leading to undesired issues or even process disruptions. Possible clogging mechanisms are categorized in Table I. Among these possible mechanisms, the first one, i.e., attachment of the nonmetallic inclusions (NMIs) on the SEN wall, is considered the major mechanism. ${ }^{[1]}$ Further discussions are presented in Section IV-C.

Recently, the current authors developed a transient model for nozzle clogging based on an Eulerian-Lagrangian approach. ${ }^{[25}$ Key features of the model are summarized as follows.

H. BARATI is with the Chair for Modeling and Simulation of Metallurgical Processes, Department of Metallurgy, Montanuniversitaet, Franz-Josef Street 18, 8700 Leoben, Austria, and also with the K1-MET, Franz-Josef Street 18, 8700 Leoben, Austria. M. WU, A. KHARICHA, and A. LUDWIG are with the Chair for Modeling and Simulation of Metallurgical Processes, Department of Metallurgy, Montanuniversitaet.

Contact e-mail: menghuai.wu@unileoben.ac.at

Manuscript submitted July 4, 2018.

Article published online March 29, 2019.
(1) The clogging process is divided into three steps: (a) transport of particles by turbulent fluid flow toward the wall, (b) interactions between the fluid and the wall and adhesion mechanism of the particle on the wall, and (c) formation and growth of the clog by the particle deposition on the clog front and the flow-clog interactions.

(2) Two different methods are used to track the particle motion: in the near-wall region using a special stochastic model ${ }^{[26]}$ for wall-bounded turbulent flow and in the bulk turbulent flow using the standard random walk model.

(3) The early stage of clogging, i.e., the deposition of NMI particles on the SEN wall to build up the initial layers of the clog, is treated as an enhancement of the SEN wall roughness, which, in turn, influences the turbulence boundary layer.

(4) An algorithm is implemented to track the clog growth, i.e., the continuous buildup of the solid materials due to further deposition of NMI particles on the clog front. The clog region is treated as a porous medium, which interacts with the fluid flow.

Preliminarily, the model was evaluated against a laboratory experiment (Figure 1). ${ }^{[25]}$ In the laboratory device, which was used for investigation of clogging, ${ }^{[5,27]}$ steel is melted in an induction furnace and deoxidized with aluminum to form solid alumina inclusions. After a certain holding time for deoxidation, the circular nozzle, situated at the bottom of the furnace, is opened and the molten steel flows through the nozzle, as shown in Figure 1(a). The nozzle is heated to prevent solidification 
in the nozzle. After a while, the nozzle may be clogged due to the buildup of the alumina inclusion on the nozzle wall. The mass flow rate of steel is dynamically monitored by weighing the mass of the steel as it is collected by a container located beneath the nozzle. Figure 1(b) indicates a typical macrograph of the as-clogged nozzle. ${ }^{[5]}$ Based on this laboratory experiment and the process parameters, the numerical model is evaluated. The numerical calculated as-clogged section (Figure 1(c)) agrees qualitatively with the experiment. A zoomed view of the clog front and the particle trajectory affected by the clog are shown in Figure 1(d). The simulations also show that the calculated mass flow rate through the nozzle during the clogging process as a function of time agrees with the experimentally monitored result. Additionally, new knowledge has been obtained from the model ${ }^{[25]}$ : (1) clogging is a transient process, and it includes the initial coverage of the nozzle wall with the deposited particles, the evolution of a bulged clog front, and then the development of a branched structure; (2) clogging is a stochastic and self-accelerating process.

Sensitivity of the model to the parameters of mesh size (hexahedron mesh), Lagrangian time scale, etc. was studied previously. ${ }^{[25]}$ The current article further evaluates the model validity for the SEN clogging during continuous casting of steel, referring to the model accuracy and calculation efficiency. One challenge to a numerical model for such engineering application is the huge number of NMI particles. The real number of particles is estimated in the order of $10^{11}$ particles (with average size of $5 \mu \mathrm{m}$ ) per ton of molten steel. During the practice of continuous casting, the clogging event would occur after $10^{2}$ tons of casting for the worst case. If all particles were accounted individually, a total number of $10^{13}$ particles would be involved. This is outside the capacity of the current computer hardware. To overcome this problem, an artificial factor, the N-factor, is necessarily introduced into the numerical model. This $\mathrm{N}$-factor is equal to the "number of representative particles." We track the motion of an individual particle in the molten steel by accounting its interactions with the turbulent flow, but this particle will represent $\mathrm{N}$ particles as it deposits on (or is captured by) the clog front or the SEN wall. With this numerical trick, the calculation efficiency will be enhanced (or the calculation time will be reduced) by the $\mathrm{N}$-factor. However, the influence of introducing this $\mathrm{N}$-factor on the calculation accuracy is not clear and will be studied here. Another numerical issue of concern is the mesh type (tetrahedron or hexahedron). Due to the complex geometry of the SEN, it is much more convenient to create tetrahedron mesh in the nozzle region. However, the numerical tracking of the clog front based on the tetrahedron mesh needs to be verified. The use of tetrahedron mesh is known to influence the accuracy of flow calculation in some cases, but it is not clear how this imperfection influences the clogging simulation.

\section{MODELING}

\section{A. Assumptions}

An Eulerian-Lagrangian model ${ }^{[25]}$ is adopted in which three main steps of clogging are taken into account: transport of particles toward the wall in a wall-bounded turbulent flow, deposition of the particles

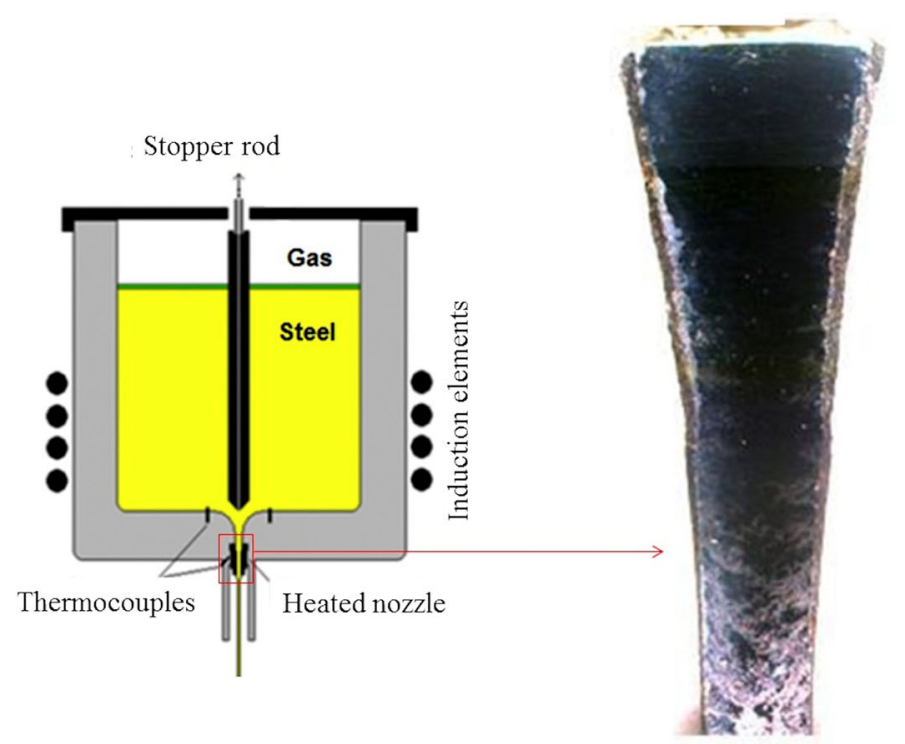

(a) (b)

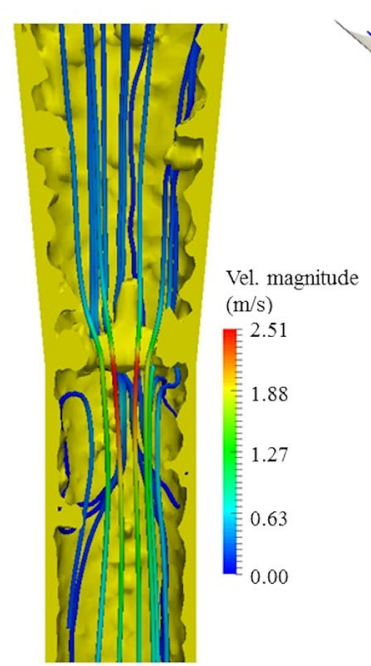

(c)

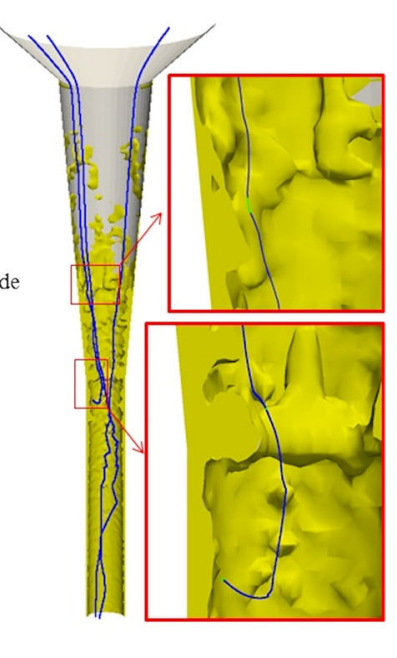

(d)

Fig. 1-A transient clogging model was used to calculate the clogging process of a laboratory experiment. (a) Schematic of laboratory device to investigate the clogging, $(b)$ typical macrograph of as-clogged nozzle (reprinted from Ref. [5]), (c) calculated flow streamlines and clog front during the clogging (reprinted from Ref. [25]), and $(d)$ trajectories of particles in the partially clogged nozzle (reprinted from Ref. [25]). The diameter of the furnace is $480 \mathrm{~mm}$ and the narrowest part of the nozzle has a diameter of $5 \mathrm{~mm}$ Copyright 2011 with permission from Taylor \& Francis and Copyright 2018 with permission from Elsevier. 
on the wall, and growth of clogging material due to the continuous particle deposition. Main assumptions and simplifications are listed subsequently.

(1) Particles are supposed to be spherical.

(2) Particles mechanically stick to the wall or the clog front as they reach it.

(3) No coagulation of particles occurs in the bulk of the fluid.

(4) Equivalent sand-grain roughness is used to treat the wall roughness.

(5) The clog is treated as a porous medium with open pores and pore fraction (porosity) is predefined as an input parameter, which can be determined experimentally from postmortem analysis of the clog sample.

(6) A volume-average scheme is used to define clog properties, e.g., porosity-dependent permeability.

(7) No detachment (fragmentation) of the clog material occurs.

(8) The fluid is considered isothermal, and no solidification of steel is assumed.

\section{B. Governing Equations for the Flow and Particle Tracking}

An Eulerian approach is employed to calculate the turbulent flow and a Lagrangian approach is used to track the motion of the particles. The fluid flow is described by the conservation equations of mass and momentum. Use of the shear-stress transport $k-\omega$ model to model turbulence is recommended because this model effectively blends the robust and accurate formulation of the $k-\omega$ model in the near-wall region with the free-stream independence of the $k-\varepsilon$ model in the far field. A key point of this model is insensitivity of flow to grid spacing near the wall. A detailed explanation can be found in References 28 and 29. The governing equations for the turbulent flow are listed in Table II. Particle motion in the bulk fluid flow is calculated based on a balance of forces applied on a particle (Table III).
Due to the difference in the turbulent flow structure between the bulk fluid region and near-wall region, a special stochastic model ${ }^{[26]}$ manages the particle motion in the near-wall region, while the standard random walk model is used for particle tracking in the bulk fluid. Details were described previously. ${ }^{[25]}$

\section{Clog Growth Algorithm}

An algorithm for clog formation and growth is schematically shown in Figure 2. The algorithm applies for both structured and unstructured meshes and for both two and three dimensions. Illustratively, only two-dimensional (2-D) meshes are used to describe the clogging procedure.

At the initial stage of clogging, deposition of NMI particles on the nozzle wall changes or enhances the roughness of the wall, which influences the turbulence kinetic energy of the flow in the near-wall region and further influences the particle motion in this region. As shown in Figures 2(a) and (b), the profile of the wall surface is presented by the equivalent "sand grain." The roughness of the wall is then quantified by the radius of the sand grain. An increase of the deposited particles is simply considered as an increase of sand grain radius in the corresponding computational cell adjacent to the wall, and the position of the wall surface is superficially presented by the line connecting the centers of the sand grains. The newly deposited particles are deleted from the calculation domain, but the corresponding mass of the deposited particles is added to the wall roughness by increasing the particles' radii by $4 / 3 \pi\left(d_{\mathrm{p}} / 2\right)^{3} /\left(\bar{f}_{\mathrm{p}} A_{\text {wall }}\right)$. $\bar{f}_{\mathrm{p}}$ is the average particle fraction of a fully clogged cell and $A_{\text {wall }}$ is area of mutual faces with the neighboring wall. $\bar{f}_{\mathrm{p}}$ is considered because the clog material is porous. When the average radius of the sand grains is larger than half the size of the boundary cell, the cell is converted to a porous medium as a "half-clogged" cell with $f_{\text {clog }}=0.5$, as shown in Figure 2(c). Here, $f_{\text {clog }}$ is the fraction of the volume that is occupied by the clog in the local computational cell. Further deposition of particles will increase $f_{\text {clog. }}$. As soon as the $f_{\text {clog }}$ reaches 1 , the

Table I. Mechanisms of SEN Clogging

\begin{tabular}{|c|c|c|c|}
\hline & Mechanism & Description & Ref.* \\
\hline 1 & deposition of indigenous NMIs & $\begin{array}{l}\text { NMI particles, as deoxidation products in the steel melt, are } \\
\text { transported toward the SEN wall, and they are deposited on the } \\
\text { SEN wall, leading to a buildup of clog layer }\end{array}$ & 2 through 7 \\
\hline 2 & thermochemical reactions & $\begin{array}{l}\text { thermochemical reactions between the SEN refractory material and } \\
\text { the steel lead to the (in-situ) formation of clog layer on the SEN wall }\end{array}$ & 8 through 15 \\
\hline 3 & local oxidation at the SEN wall & $\begin{array}{l}\text { negative pressure inside the SEN results in oxygen drawing through } \\
\text { the SEN refractory (porous) material into the inner SEN wall; and } \\
\text { the oxygen reacts with the steel melt to form oxides on the SEN wall }\end{array}$ & 16 through 18 \\
\hline 4 & precipitation of NMIs & $\begin{array}{l}\text { temperature drop of the melt near the SEN wall leads to lower } \\
\text { solubility of oxygen in the steel melt and subsequent precipitation of } \\
\text { alumina at SEN-steel interface }\end{array}$ & 19,20 \\
\hline 5 & possible solidification of the steel & $\begin{array}{l}\text { if superheat of the melt is low and heat transfer from the SEN is high, } \\
\text { the steel may solidify at the SEN wall }\end{array}$ & 21 through 24 \\
\hline
\end{tabular}

*This reference list cannot collect all contributions, but it provides further sources with more detailed description about the clogging mechanisms. 
Table II. Governing Equations for the Fluid Flow

Conservation Equations

Symbol Definition

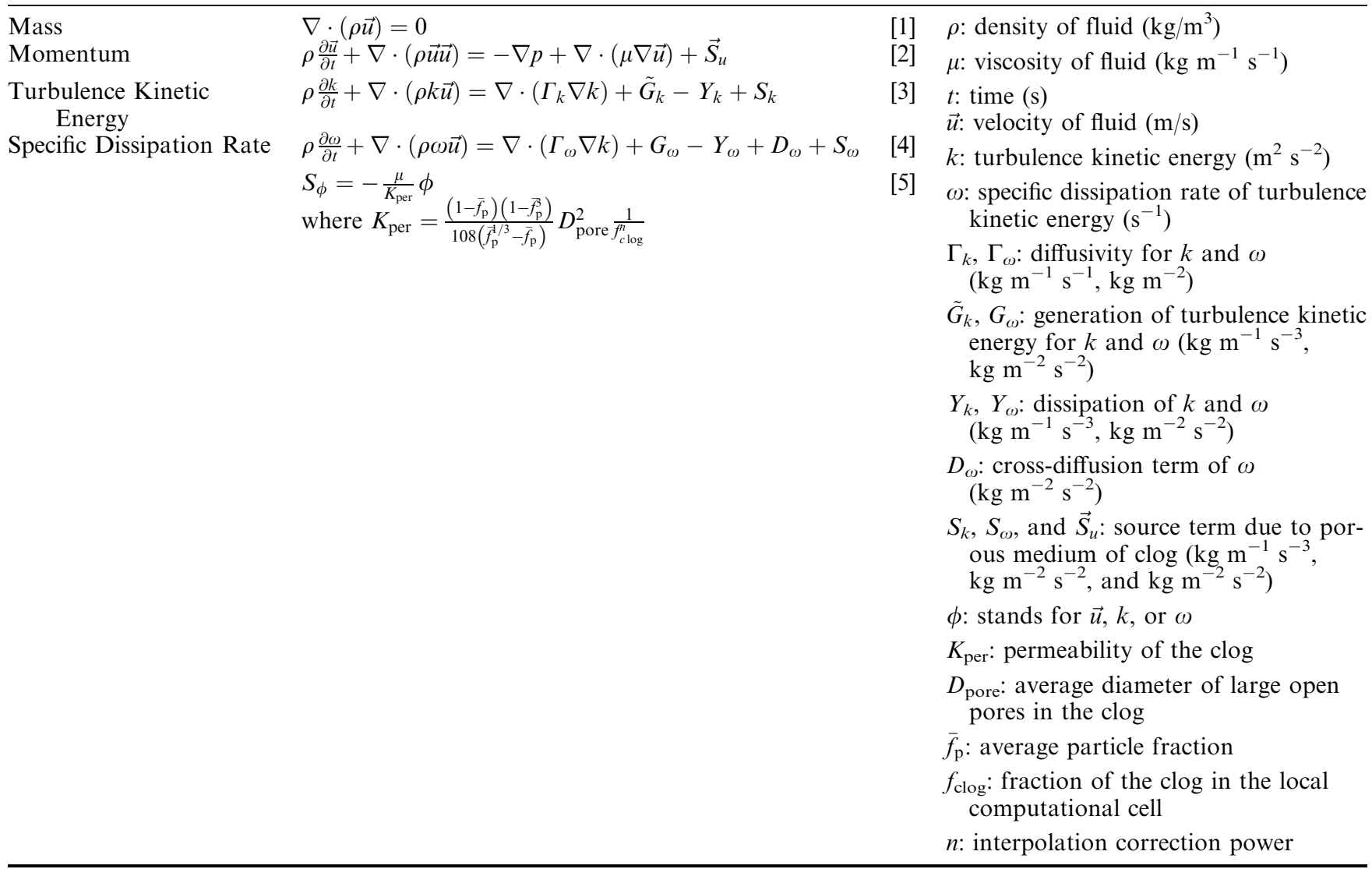

Table III. Equations for Forces Acting on a Particle in Bulk Flow

Transport Equation

Symbol Definition

\begin{tabular}{|c|c|c|c|}
\hline Buoyancy Force & $\begin{array}{l}m_{p} \frac{d \vec{u}_{p}}{d t}=\vec{F}_{B}+\vec{F}_{D}+\vec{F}_{L}+\vec{F}_{\mathrm{VM}}+\vec{F}_{\text {press }} \\
\vec{F}_{\mathrm{B}}=\frac{\left(\rho_{\mathrm{p}}-\rho\right) \pi d_{\mathrm{p}}^{3}}{6} \vec{g}\end{array}$ & $\begin{array}{l}{[6]} \\
{[7]}\end{array}$ & $\begin{array}{l}\vec{g}: \text { gravity }\left(\mathrm{m} \mathrm{s}^{-2}\right) \\
\rho_{\mathrm{p}}: \text { density of particle }\left(\mathrm{kg} \mathrm{m}^{-3}\right) \\
d_{\mathrm{p}}: \text { diameter of particle }(\mathrm{m}) \\
C_{\mathrm{D}}: \text { drag coefficient }(-)\end{array}$ \\
\hline \multirow[t]{3}{*}{ Drag Force } & $\vec{F}_{\mathrm{D}}=\frac{1}{8} \pi d_{\mathrm{p}}^{2} \rho C_{\mathrm{D}}\left|\overrightarrow{u^{\prime}}-\vec{u}_{\mathrm{p}}\right|\left(\overrightarrow{u^{\prime}}-\vec{u}_{\mathrm{p}}\right)$ & {$[8]$} & $\mathrm{Re}_{\mathrm{p}}$ : particle Reynolds number $(-)$ \\
\hline & $C_{\mathrm{D}}=\left\{\begin{array}{cc}\frac{24}{\mathrm{Re}_{\mathrm{p}}}, & \mathrm{Re}_{\mathrm{p}}<0.1 \\
\frac{24}{\operatorname{Re}_{\mathrm{p}}}\left(1+0.15 \mathrm{Re}_{\mathrm{p}}^{0.687}\right), & 0.1 \leq \mathrm{Re}_{p} \leq 10^{3} \\
0.44, & \operatorname{Re}_{p}>10^{3}\end{array}\right.$ & & $\begin{array}{l}U_{\mathrm{s}}: \text { difference between instantaneous } \\
\quad \text { streamwise velocities for fluid and } \\
\text { particle }\left(\mathrm{m} \mathrm{s}^{-1}\right) \\
G: \text { local velocity gradients }\left(\mathrm{s}^{-1}\right) \\
J: \text { correction factor of the lift force }(-)\end{array}$ \\
\hline & $\operatorname{Re}_{\mathrm{p}}=\frac{\left|\vec{u}-\vec{u}_{\mathrm{p}}\right| d_{\mathrm{p}} \rho}{\mu}$ & & \\
\hline Lift Force & $\vec{F}_{\mathrm{L}}=-\frac{9}{4 \pi} \mu d_{\mathrm{p}}^{2} U_{\mathrm{s}} \operatorname{sgn}(G)\left(\frac{\rho}{\mu}|G|\right)^{1 / 2} J$ & [9] & \\
\hline Virtual Mass Force & $\vec{F}_{\mathrm{VM}}=\frac{\rho \pi d_{\mathrm{p}}^{\beta}}{12} \frac{\mathrm{d}}{\mathrm{d} t}\left(\vec{u}-\vec{u}_{\mathrm{p}}\right)$ & {$[10]$} & \\
\hline Pressure Gradient Force & $\vec{F}_{\text {press }}=\frac{\rho \pi d_{\mathrm{p}}^{3}}{6} \frac{D \vec{u}}{D t}$ & {$[11]$} & \\
\hline
\end{tabular}




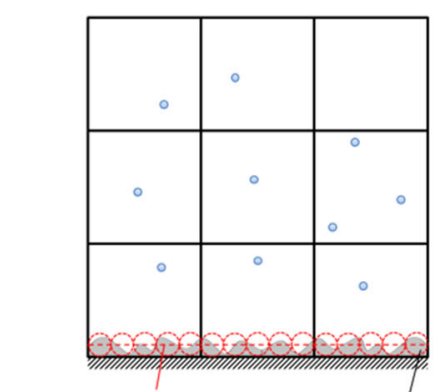

position of superficial surface arbitrary roughness profile

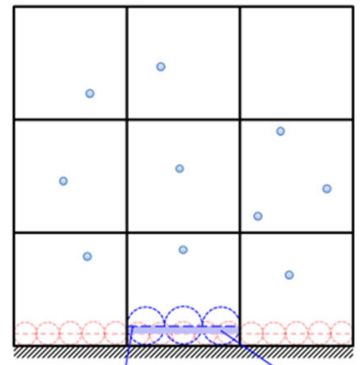

new position of superficial surface

thickness of deposition

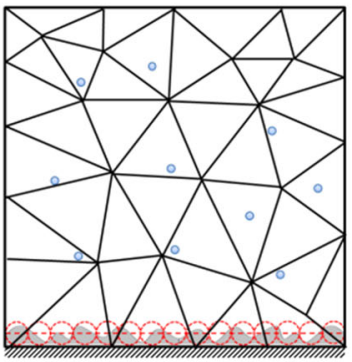

(a)

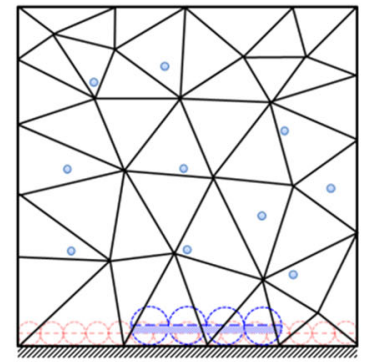

(b)
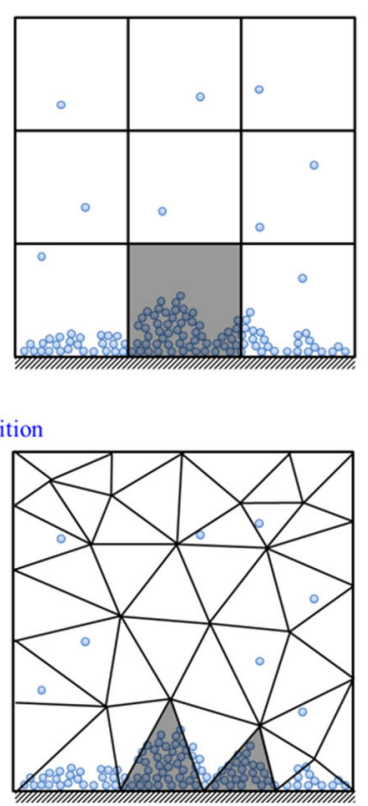

(c)
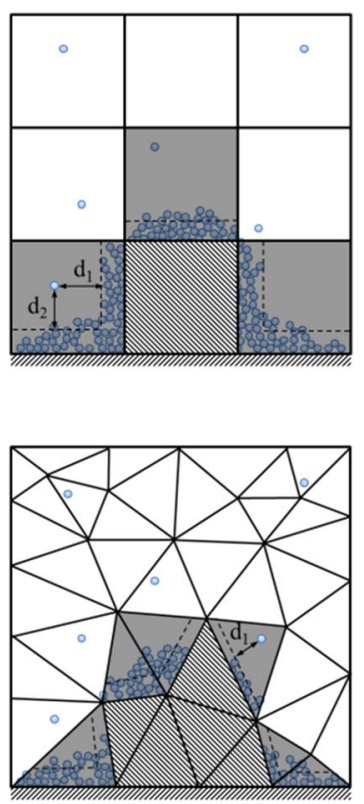

(d)

Fig. 2-Algorithm of clog formation/growth. For better visualization, meshes are shown in a 2-D view, although the algorithm can be applied for both two and three dimensions. Illustratively, two mesh types are shown: hexahedron (top row) and tetrahedron (bottom low). (a) Initial wall roughness considered as uniform sand-grain roughness calculated from an arbitrary roughness profile; $(b)$ enhancement of the wall roughness due to the particle deposition in the wall boundary cells; (c) formation of the porous region of the clog by partially clogged cells marked in gray; $(d)$ formation of fully clogged cells, filled by hatch pattern, and continuous growth of the clog into the bulk region.

\section{Table IV. Physical Properties and Numerical Parameters}

\begin{tabular}{ll}
\hline Density of Steel Melt $\left(\mathrm{kg} \mathrm{m}^{-3}\right)$ & 7200 \\
Density of Particle $\left(\mathrm{kg} \mathrm{m}^{-3}\right)$ & 3700 \\
Viscosity of Steel Melt $\left(\mathrm{kg} \mathrm{m}^{-1} \mathrm{~s}^{-1}\right)$ & 0.006 \\
Diameter of Particles $(\mu \mathrm{m})$ & $2-10$ \\
Time-Step for Flow Calculation $(\mathrm{s})$ & 0.01 \\
Average Volume Fraction of Solid Particles $\left(\bar{f}_{\mathrm{p}}\right)$ & 0.55 \\
Average Pore Diameter in the $c \log (\mu \mathrm{m})$ & 20 \\
Number of Representative Particles $(\mathrm{N}-$ Factor $)$ & $1-1257$
\end{tabular}

status of the boundary cell will be changed from a "partially clogged" cell to a "fully clogged" cell and, correspondingly, the status of the neighbor cells in the bulk region will be changed from "no clog" to partially clogged cells. Numerically, the statuses of the computational cells (no clog, partially clogged, or fully clogged) are marked by a cell index.

In a partially clogged cell, a uniform layer of the clog is assumed to cover the mutual cell faces with neighboring fully clogged cells or wall, depicted by the dashed line in Figure 2(d) as the clog front. All particles entering the partially clogged cells can potentially deposit, as shown in Figure 2(d). When the distance of a particle from the clog front in the partially clogged cell is smaller than the radius of the particle, the particle will deposit or adhere to the clog front. The clog front is calculated by assuming there is a uniform distribution of clog on mutual faces with neighboring fully clogged cells or the wall in a partially clogged cell. In other words, the clog volume in a partially clogged cell is divided by the total area of mutual faces with neighboring fully clogged cells or the wall to calculate the clog thickness (position of the clog front). Again, this deposited particle will be removed from the calculation domain and the corresponding mass will be added to the clog material; also, the value of $f_{\text {clog }}$ increases. Then, the volume of the particle is added to the particle fraction (solid fraction) of the cell $\left(f_{\mathrm{p}}\right)$ and is removed from the calculations. Since a constant value is assumed for the average particle fraction of a fully clogged cell $\left(\bar{f}_{\mathrm{p}}\right), f_{p}=f_{\text {clog }} \cdot \overline{\mathrm{p}}_{\mathrm{p}}$. Postmortem analysis of the particulate clogging materials in an as-clogged SEN nozzle declares that the clog is a porous medium with open pores. ${ }^{[27]}$ Hence, a source term is applied in momentum and turbulence equations to implement the effects of the porous clog, with an average pore diameter of $D_{\text {pore }}$, on the fluid flow using Eq. [5] in Table II.

\section{Simulation Settings}

This study targets steel melt. The particle is NMI (alumina). The particle size (diameter) is in the range of 2 to $10 \mu \mathrm{m}$, which is according to the experimental analysis of the as-clogged SEN nozzle. ${ }^{[30]}$ Properties of these materials and other parameters are listed in Table IV. The equations are numerically solved using the commercial computational fluid dynamics (CFD) code ANSYS-FLUENT with extended user-defined functions for considering the particle deposition and the growth of the clog. All computations are done on a high-performance computer cluster with 12 CPUs (2.9 $\mathrm{GHz}$ ). The computation time for different case varies between 9.5 and 182.5 hours depending on the number of particles. Note that the particle tracking takes most of the calculation time. 


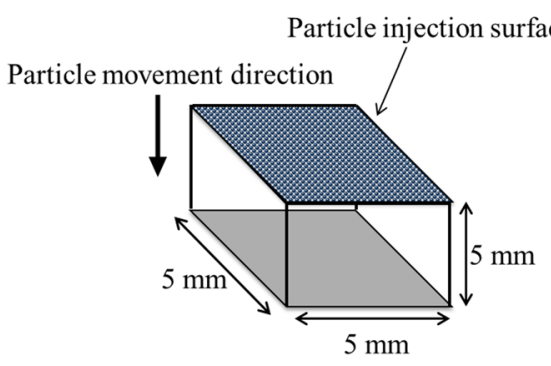

(a)

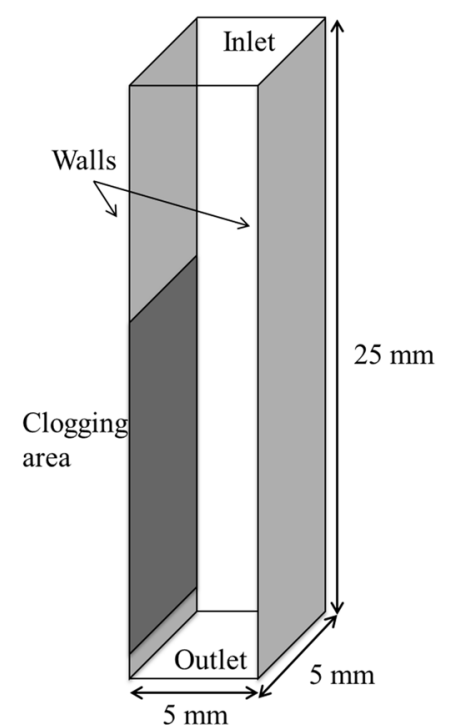

(b)
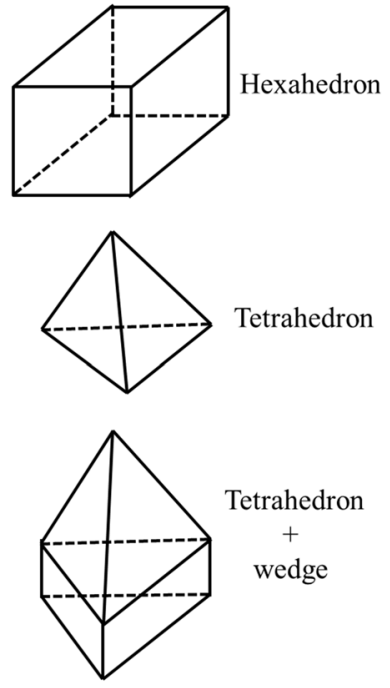

(c)

Fig. 3 - Computational domain and boundary conditions to study mesh dependency of the clog growth algorithm $(a)$ without and $(b)$ with the effect of the fluid flow, and $(c)$ different mesh types used in the current study.
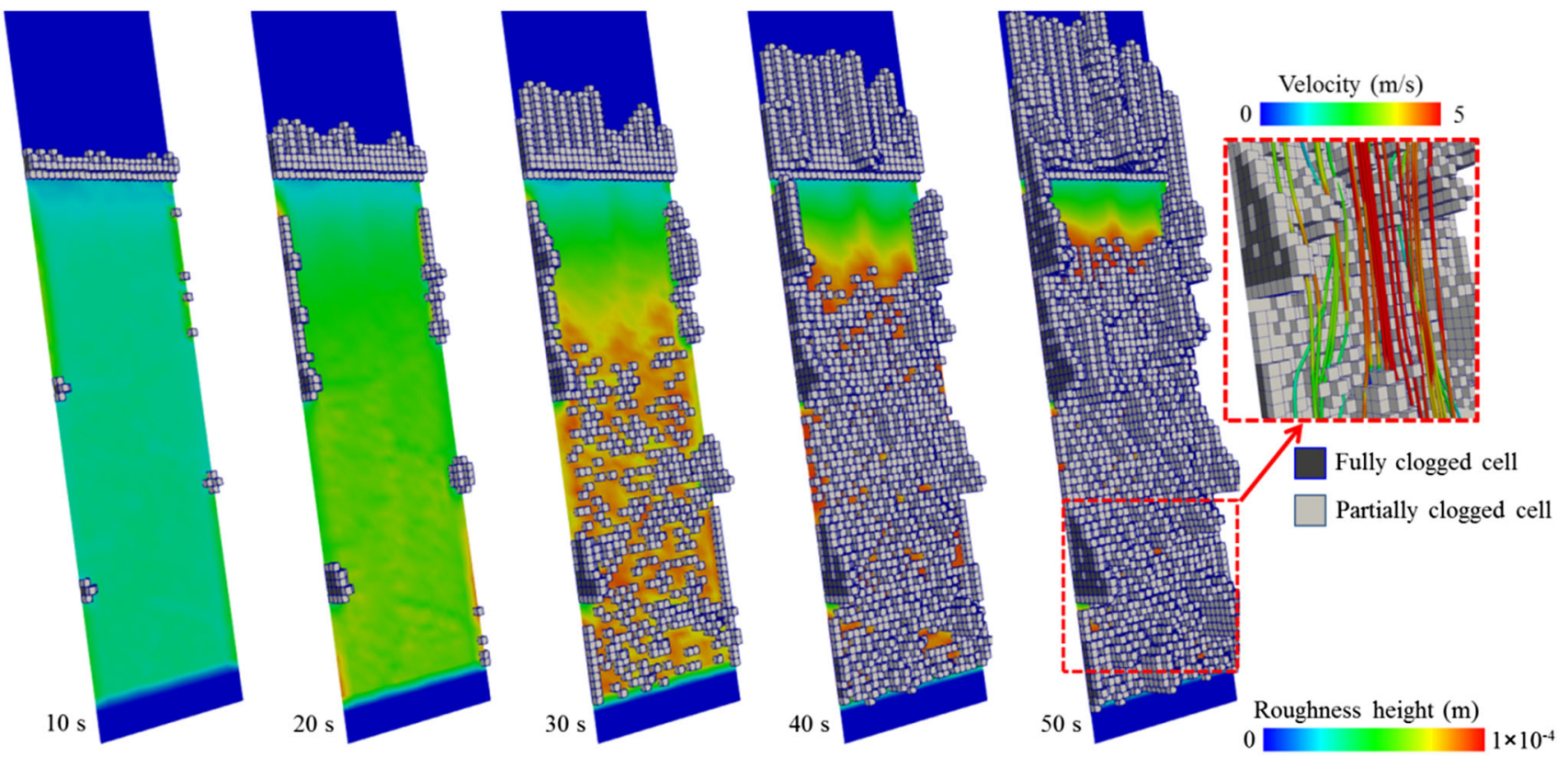

Fig. 4-Modeling result of the transient clog growth for case 2. The fully clogged cells (dark) and partially clogged cells (light) are shown. The roughness height of the wall (diameter of the equivalent sand grain) enhanced by the particle deposition is shown by the color scale. A zoomed view with flow streamlines is shown for the moment at $50 \mathrm{~s}$. Mesh type is hexahedron (Color figure online).

\section{PARAMETER STUDIES}

Two numerical issues are studied in the current article: (1) the validity of different mesh types for tracking the clog growth and (2) sensitivity of the clogging model to the introduced artificial number of representative parti- cles ( $\mathrm{N}$-factor). Other issues regarding the choice of the modeling parameters of mesh size, Lagrangian time scale, the porosity of the clog, and the correction factor in the interpolation of clog permeability are investigated and discussed in the previous work. ${ }^{[25]}$ 

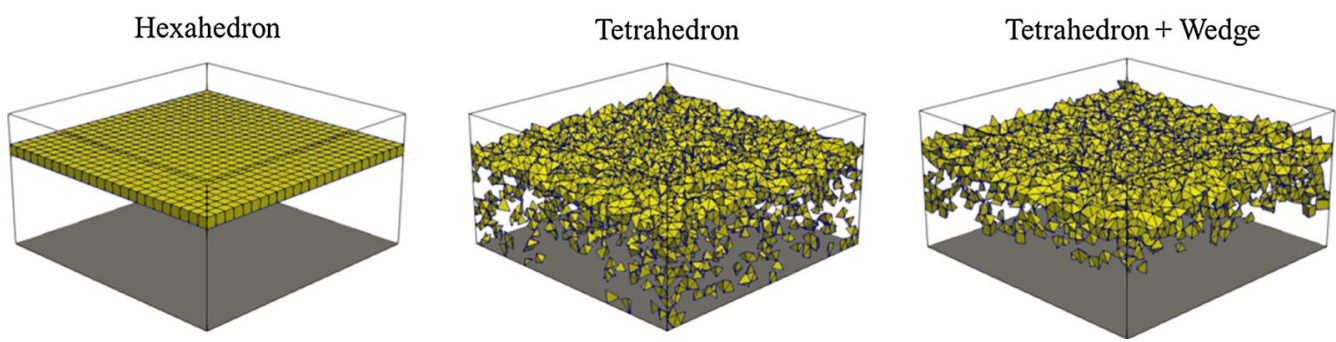

Fig. 5-Effect of mesh type on the tracking of clog front. Only partially clogged cells are shown (yellow). This result is shown when all injected particles (45 million) are deposited (Color figure online).

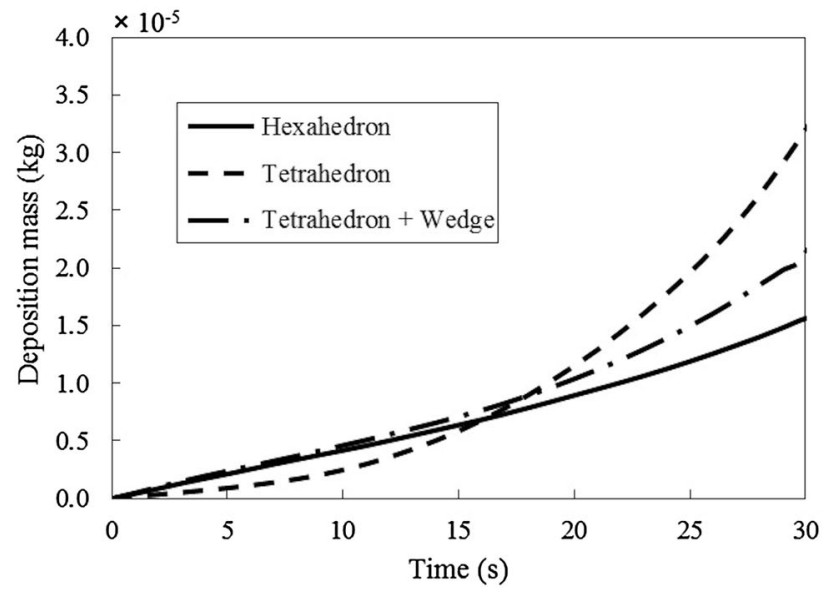

(a)

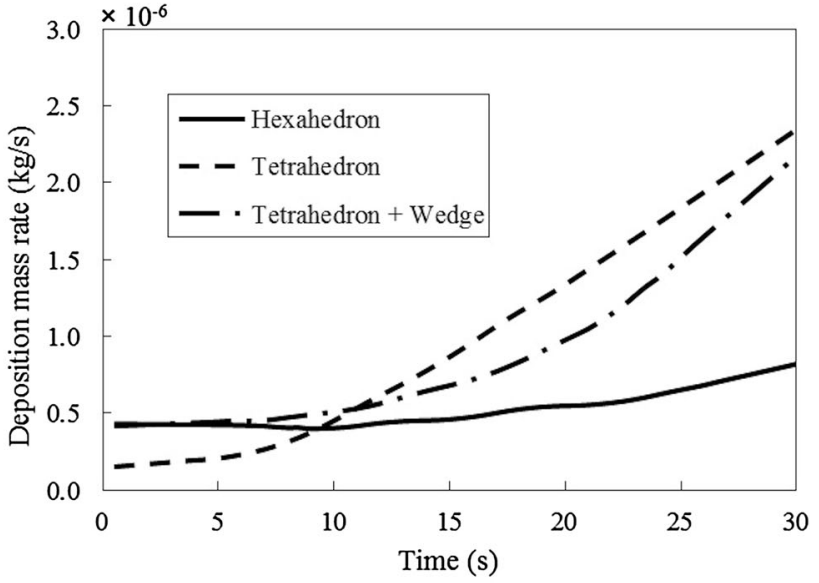

(b)

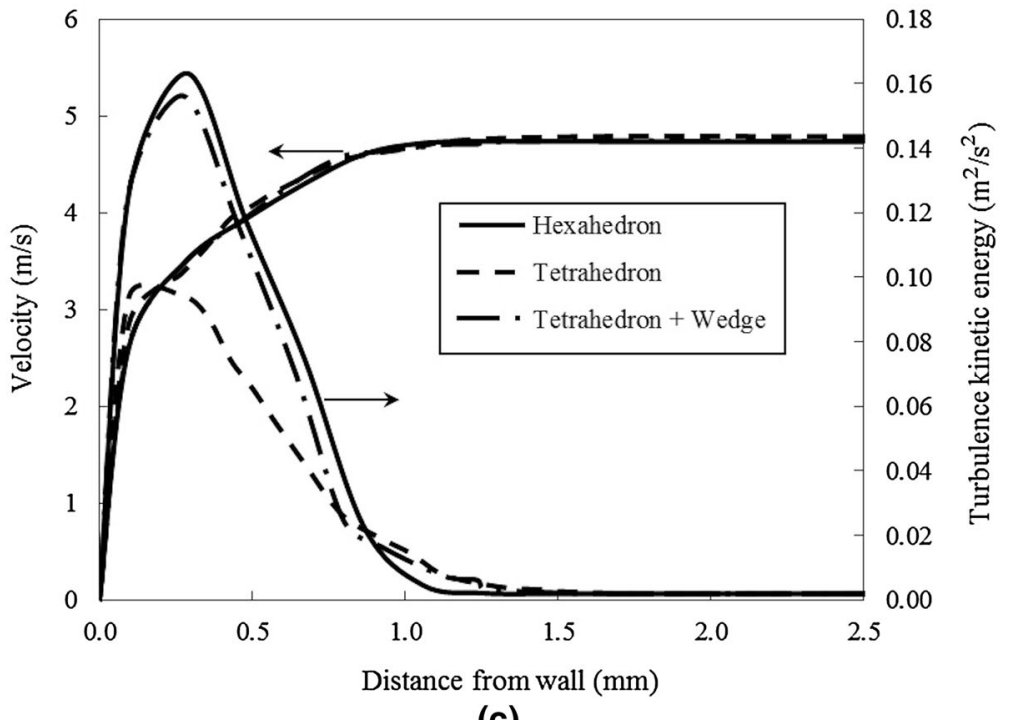

(c)

Fig. 6 - (a) Total particle deposition mass and (b) its rate as a function of time and $(c)$ profiles of velocity and turbulence kinetic energy for different mesh types. 
Table V. Numerical Studies of the Effects of N-Factor on the Clogging (the Total Mass Injection Rate of Particles at the Inlet Is Constant: $\left.1.33 \times 10^{-5} \mathrm{~kg} / \mathrm{s}\right)$

\begin{tabular}{lll}
\hline$d_{\mathrm{p}}(\mu \mathrm{m})$ & \multicolumn{1}{c}{ N-Factor } & Particle Number Injection Rate (Million Particles Per Second) \\
\hline 2 & $1,10,25,78,157,314,628,1257$ & $860,85.5,34.2,10.944,5.472,2.736,1.368,0.684$ \\
4 & $1,6,10,31,78,157$ & $102.6,17.1,10.26,3.42,1.368,0.684$ \\
6 & $1,3,6,9,23,47$ & $30.78,10.26,5.472,3.42,1.368,0.684$ \\
8 & $1,3,5,10,20$ & $12.996,4.788,2.736,1.368,0.684$ \\
10 & $1,3,5,10$ & $6.84,2.052,1.368,0.684$ \\
\hline
\end{tabular}

\section{A. Mesh Type}

\section{Test cases}

It is well known that the CFD calculation of flow field depends on the mesh quality. In order to validate the algorithm for clog growth (Section II-C), two case studies are separately performed: (1) an ideal case of "pure" clog growth due to the particle deposition without the effect of fluid flow and (2) a reality-close case of clog growth combining the particle deposition and the effect of fluid flow.

Although case 1 is not realistic, it helps to study exactly the effect of the mesh type on the modeling accuracy for the clog growth. As depicted in Figure 3(a), a simple cubic calculation domain is designed, where no flow is involved. Particles are injected with a uniform distribution from the inlet (top) vertically downward, and they move with equal speed toward the wall (bottom). Particles stop once they meet the wall or clog front. The diameter of particles is $10 \mu \mathrm{m}$, and 45 million particles are injected in total.

The computational domain for case 2, which includes the effect of fluid flow, is depicted in Figure 3(b). Two parallel walls with $5-\mathrm{mm}$ distance are designed. A fully developed flow with mean velocity of $5 \mathrm{~m} / \mathrm{s}$ is assigned to the inlet at the top boundary, and the pressure outlet is imposed for the outlet at the bottom boundary. The values for average fluid velocity and distance between two walls are extracted from typical results of flow of molten steel through the gap between the stopper and SEN during the continuous casting of steel. The front and back boundaries are symmetrical planes. No-slip conditions with an initial roughness height of $10 \mu \mathrm{m}$ are applied on the walls. To have better visualization of the clog growth, a certain area of the walls is defined for particle deposition, as highlighted (dark gray) in Figure 3(b). In the other area of the wall (light gray), the rebound boundary condition is imposed for particles. Particles with a diameter of $10 \mu \mathrm{m}$ are injected at the inlet with a constant mass injection rate. Since two walls are exposed to the same conditions, only one wall is considered and the calculation domain is from the left wall to a parallel plane located exactly in the middle of two walls; i.e., a half of the geometry, as shown in Figure 3(b), is simulated.

As shown in Figure 3(c), three types of mesh are studied for both cases 1 and 2. Hexahedron and tetrahedron are mostly used in CFD calculation. Sometimes a combination of wedge mesh near the wall and tetrahedron in the inner region is used as well. The mesh size is uniform in all simulations. The mesh sizes for pure clog growth (Figure 3(a)) and for clog growth with flow (Figure 3(b)) are 0.4 and $0.2 \mathrm{~mm}$, respectively, for all mesh types.

\section{Results}

\section{a. Transient clog growth}

Modeling results of the transient clog growth (case 2, with flow) are shown in Figure 4. The partially clogged cells, shown as light gray, surround the fully clogged cell, shown as dark gray. The fully clogged cells can be seen on the left section. The wall roughness height enhanced by particle deposition at the initial stage is shown by contours on the wall. At 10 seconds, a band of fully and partially clogged cells form on the top of the clogging area. In the rest of the wall (clogging area), particles are mostly deposited to enhance the wall roughness (at the initial stage of clogging). The enhanced wall roughness (diameter of the equivalent sand grain), shown by color scale, is still smaller than half of the cell size; hence, no partially clogged cell is observed.

The clog tends to grow against the flow direction, as seen from the results at 20,30,40, and 50 seconds. Other fully and partially clogged cells are distributed erratically (randomly) on the clogging area, preferably near the symmetry planes. A zoomed view of the flow streamlines with partially and fully clogged cells is shown for the result at 50 seconds (Figure 4). This view indicates how clog growth results in a change in the flow pattern and, consequently, changes in the deposition of the particles.

\section{b. Clog growth without flow (case 1)}

The pure clog growth under the simplified circumstance without flow is calculated, and the calculation domain is described in Figure 3(a). The calculation results of the clog front, using different mesh types, are shown in Figure 5. The partially clogged cells (yellow) define the clog front; the fully clogged cells (below the clog front) are not shown. The result with hexahedron mesh represents the precise result. The clog front is (should be) smooth and flat, as the particles are uniformly injected from the inlet (top) and homogenously deposited on the wall or clog front. The calculation with the tetrahedron mesh, however, shows that the clog front is not flat and some partially clogged cells are even embedded in the fully clogged region (this should not 


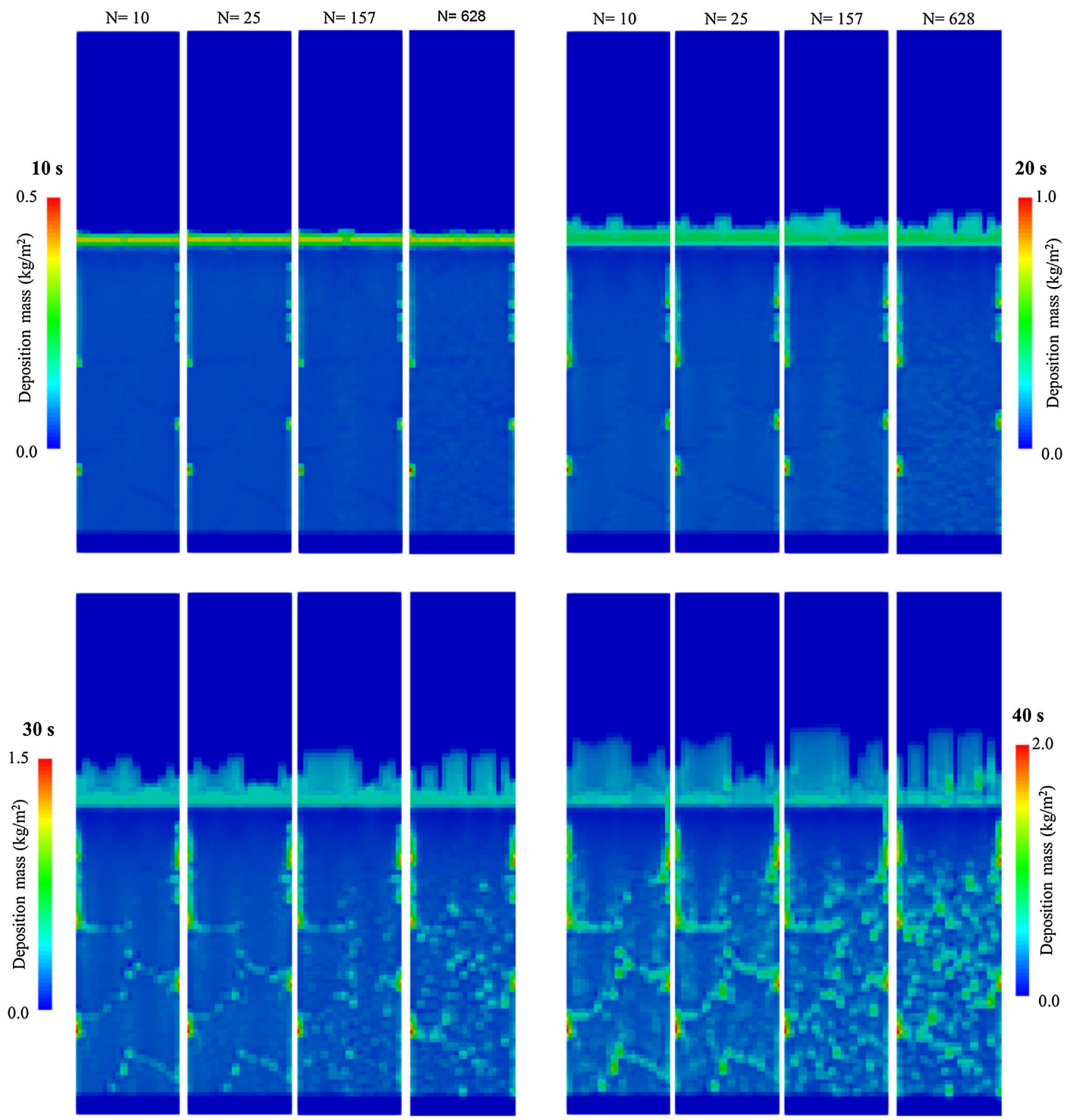

Fig. 7-Evolutions of the mass deposition $\left(\mathrm{kg} / \mathrm{m}^{2}\right)$ on the wall for selected simulation cases with $\mathrm{N}$-factor $\left(10,25,157\right.$, and $\left.628 ; d_{\mathrm{p}}=2 \mu \mathrm{m}\right)$. Results of four different moments (time $=10,20,30$, and $40 \mathrm{~s}$ ) are shown. The deposition mass $\left(\mathrm{kg} / \mathrm{m}^{2}\right)$ in color scale represents the total mass of deposited particles, which is projected onto the wall (facilitating a 2-D presentation) (Color figure online).

occur in this case). Because the size and orientation of each cell in the tetrahedron mesh are different, some cells, in preferable orientation, would be more easily occupied by the clog than other cells. If the cells in the upstream direction are occupied sooner than the downstream cells, these downstream cells would remain partially clogged. In the case with wedge mesh near the wall and tetrahedron mesh in the bulk, some cells are also left below the clog front as partially clogged cells. However, in the wedge region, no partially clogged cell is seen, except for a few cells, which are located in the border to the tetrahedron region. At the border, some tetrahedron neighbor cells, in preferable orientation, are occupied sooner than some wedge cells below. The tetrahedron mesh region (above the wedge region) behaves similarly as the last case, and some partially clogged cells remain below the clog front. As a conclusion to this study, both hexahedron mesh and wedge mesh are suitable for tracking the clog front. The current algorithm for clog growth does not apply for 


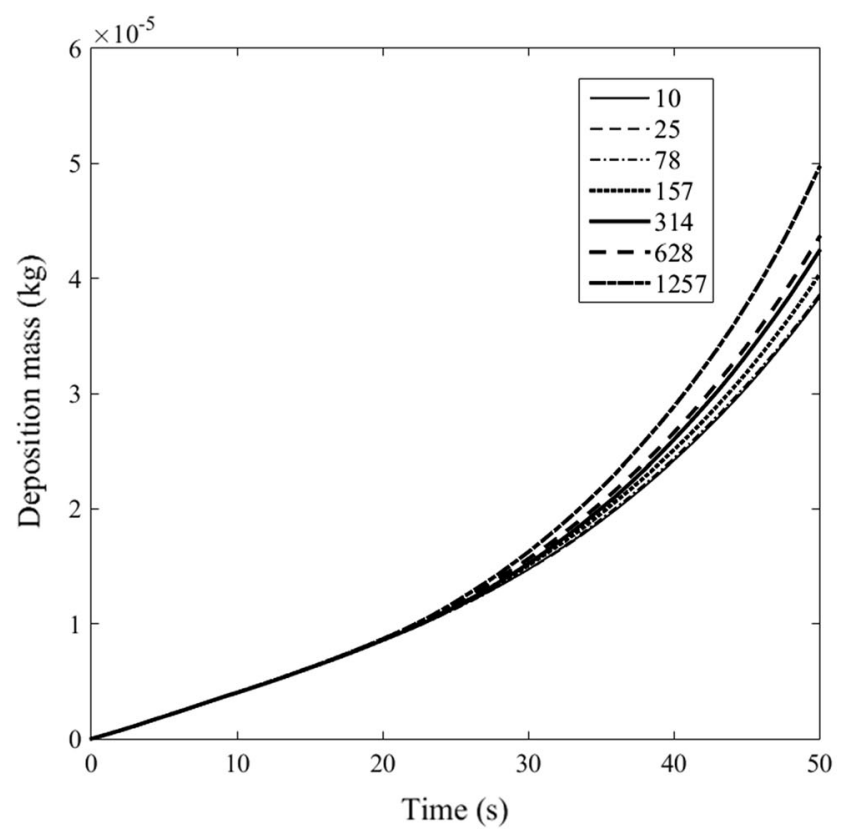

(a)

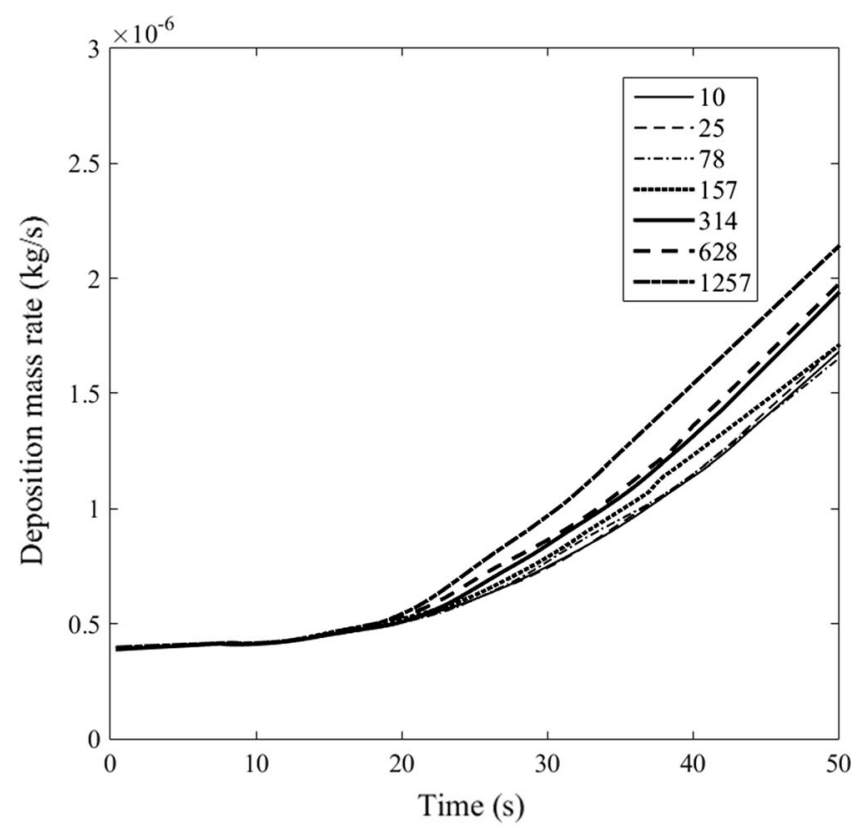

(b)

Fig. 8- (a) Total particle deposition mass and $(b)$ its rate, and their dependence on the N-factors. $d_{\mathrm{p}}=2 \mu \mathrm{m}$.

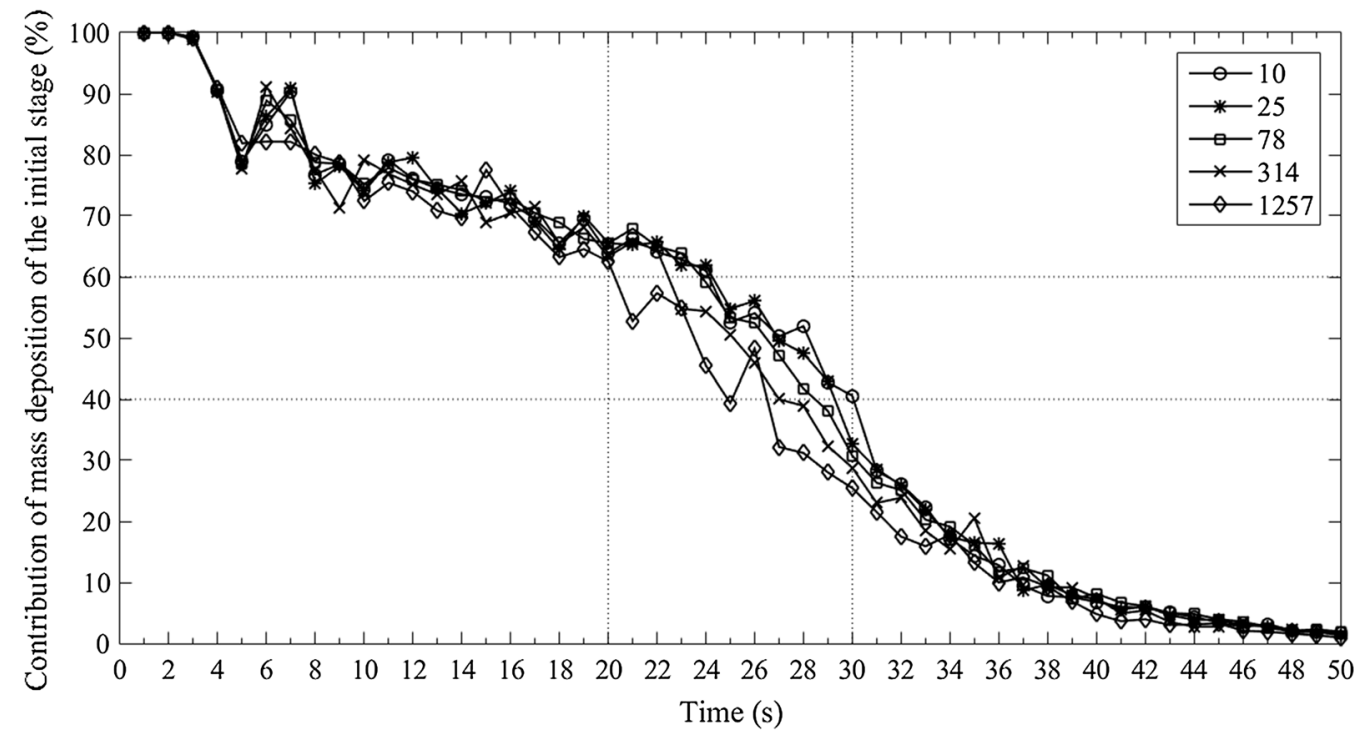

Fig. 9- Contribution of mass deposition by means of wall roughness enhancement in every $1 \mathrm{~s}$. It is calculated as a fraction of mass deposition due to the initial clog growth (enhancing the wall roughness) respecting the total mass deposition (mass pct). $d_{\mathrm{p}}=2 \mu \mathrm{m}$.

tetrahedron mesh. Further discussions are made in Section IV-B. It should be mentioned that in this simulation case (case 1), results are independent of mesh size.

\section{Clog growth with flow (case 2)}

The calculation domain for this study is shown in Figure 3(b). Typical clog growth is described in Section III-A-1-a (Figure 5). The total particle deposition mass (kilogram), i.e., the integral of the mass of clog materials over the entire wall, is plotted as a function of time (Figure 6(a)). The mass deposition rate (kilograms per second), i.e., the time derivative of the total particle deposition mass, is plotted in Figure 6(b). The results, as calculated with different mesh types, are also compared. Since clogging is a self-accelerating phenomenon, ${ }^{[25]}$ and imposed constant mass flow rate is applied at the inlet, the deposition mass rates increase with the time for all mesh types. The results indicate that until 10 seconds, deposition mass and its rate for hexahedron mesh and tetrahedron with wedge are very close. After 10 seconds, the deposition rate for tetrahedron with wedge increases 


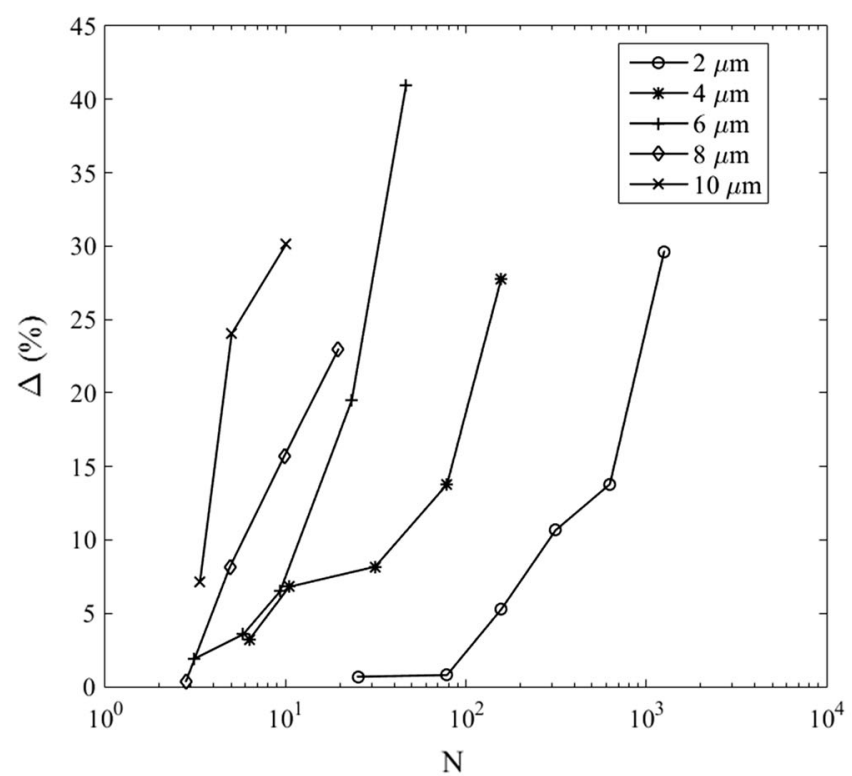

(a)

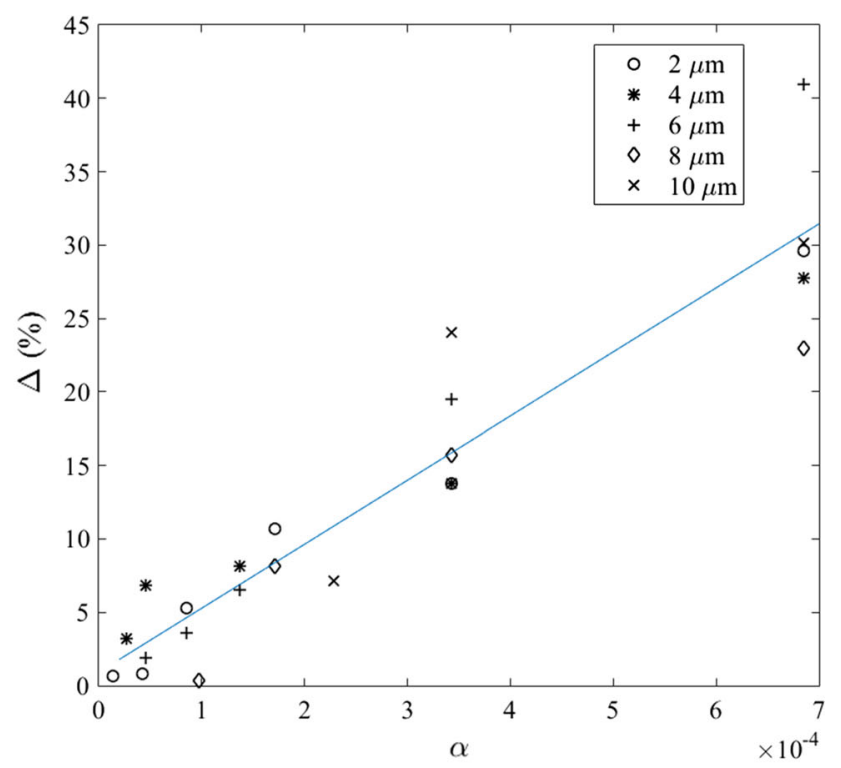

(b)

Fig. 10 - Numerical study of the calculation accuracy and its dependency on $\mathrm{N}$-factor. (a) The deviation factor $\Delta$ as a function of $\mathrm{N}$-factor. (b) The deviation factor $\Delta$ as a function of $\alpha$. The clogging result is evaluated for different particle sizes at the moment of $50 \mathrm{~s}$.

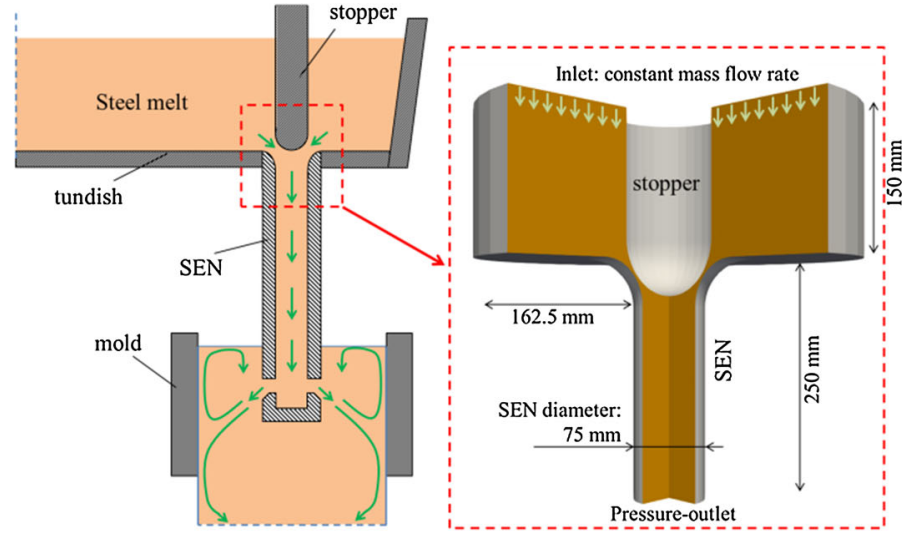

(a)

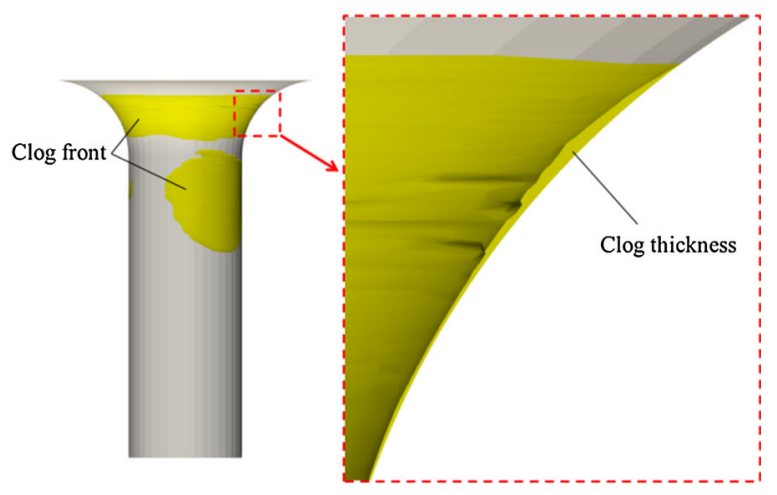

(b)

Fig. 11-(a) Schematic of steel continuous casting machine and the calculation domain for simulation of clogging in SEN and (b) the preliminary results of clog growth in SEN after $30 \mathrm{~min}$.

with a larger slope than that for hexahedron. The deposition rate for tetrahedron mesh at the early stage of clogging is small, but after around 5 seconds, it increases suddenly with a larger slope than that for the two other mesh types. This behavior results in a large difference in the total deposition mass between different mesh types. At 30 seconds, the deposition mass rate for the tetrahedron mesh is about 2 times larger than that for the hexahedron mesh and it is significantly overestimated.

In Figure 6(c), profiles of velocity and turbulence kinetic energy are plotted for different mesh types. The velocity profile is similar for all mesh types, but the turbulence kinetic energy for tetrahedron mesh is smaller than that of the two other mesh types. The difference in turbulence kinetic energy indicates why tetrahedron results in smaller particle deposition in the early stage of clogging. The difference in deposition results in the later stage of clogging is discussed in Section IV-B.

\section{B. N-Factor}

\section{Test cases}

This study is performed with the benchmark configuration of Figure 3(b); i.e., the flow effect is included for consideration. To study the sensitivity of the model to the $\mathrm{N}$-factor, 29 simulations were made, as listed in Table $\mathrm{V}$, by varying the $\mathrm{N}$-factor, particle diameter $\left(d_{\mathrm{p}}\right)$, and number injection rate. The total mass injection rate of particles from the inlet in each simulation case is kept constant, $1.33 \times 10^{-5} \mathrm{~kg} / \mathrm{s}$. For example, for the 
simulation case $\left(\mathrm{N}\right.$-factor $\left.=1 ; d_{\mathrm{p}}=2.0 \mu \mathrm{m}\right)$, the particle number injection rate at the inlet must be 860 million per second; for another case $(\mathrm{N}$-factor $=1257$; $d_{\mathrm{p}}=2.0 \mu \mathrm{m}$ ), the particle number injection rate at the inlet must be 0.684 million per second. It should be mentioned that under the condition of constant mass injection rate at the inlet, the $\mathrm{N}$-factor cannot always be an integer number; however, in this article, the rounded value of the $\mathrm{N}$-factor is reported, which looks like an integer. With the increase of the $\mathrm{N}$-factor, the total number of particles for the simulation decreases by a factor of $\mathrm{N}$; to treat the flow-particle (hydrodynamic) interactions, each particle represents only one particle. As soon as the particle deposits on (or is captured by) the clog front, one particle represents $\mathrm{N}$ particles.

\section{Results}

The evolutions of the mass deposition $\left(\mathrm{kg} / \mathrm{m}^{2}\right)$ on the wall for selected simulation cases $(\mathrm{N}$-factor $=10,25$, 157, and 628; $d_{\mathrm{p}}=2 \mu \mathrm{m}$ ) are presented in Figure 7. The mass deposition at the initial stage (resulting in enhancement of the wall roughness) is also included. In principle, all four cases are similar. Before 20 seconds, almost no difference can be seen for all four cases; a horizontal clogging band is seen on the top edge of the clogging area and several spots are shown near the symmetry planes, corresponding to the result of Figure 4. After 30 seconds, for the first two cases (N-factor $=10$ and 25), the results are almost identical; the two other cases $(\mathrm{N}$-factor $=157$ and 628) show slightly more difference, but the difference is not evident.

In Figure 8, the particle deposition mass (kilogram), i.e., the integral of the mass of clog materials over the entire wall, and the mass deposition rate (kilograms per second), i.e., the time derivative of the total particle deposition mass, are analyzed. The effect of the N-factor on the clogging can be more quantitatively identified. Obviously, all curves with different $\mathrm{N}$-factors are almost identical before 20 seconds. After 20 seconds, generally, the higher value of the $\mathrm{N}$-factor leads to a higher deposition mass. However, the curves for $\mathrm{N}<100$ are almost overlaid with each other.

As explained in Section II-C, the numerical model (algorithm) treats the clogging process in two stages: the initial stage of particle deposition on the wall, which enhances the wall roughness, and the second stage of clog growth (to consider the clog growth as a porous medium). A hypothesis to explain the effect of the $\mathrm{N}$-factor on the clogging, as shown in Figure 8, is due to the transition to the second clog growth stages. The

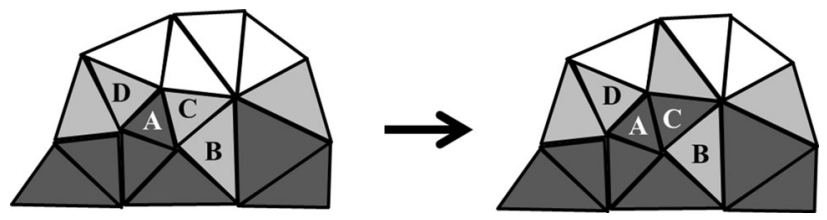

Fig. 12 - Schematic illustration of how a partially clogged cell may be surrounded by fully clogged cells in an unstructured tetrahedron mesh. Fully clogged and partially clogged cells are shown with dark and light gray, respectively. algorithm for the initial stage with the enhanced wall roughness ignores the potential buildup of the network of a porous medium. Note that the initial roughness of the SEN wall is set to $\sim 10 \mu \mathrm{m}$, which is close to the size of the NMIs. This implies that deposition of a few layers of particles with size 2 to $10 \mu \mathrm{m}$ can enhance the wall roughness in the order of the initial wall roughness.

To further verify the preceding hypothesis, we separate the mass deposition due to the initial clog growth (enhanced wall roughness) from the total mass deposition by defining a so-called "contribution of mass deposition by wall roughness enhancement" (mass percent). The results of calculations with different $\mathrm{N}$-factors are shown in Figure 9. The curves start from 100 pct; i.e., all mass deposition is initially due to the algorithm by the wall roughness enhancement. With time, the contribution due to this algorithm reduces gradually. To the moment of 20 seconds, about $60 \mathrm{pct}$ of the deposition mass is consumed to enhance the wall roughness; correspondingly, the rest of the 40 pct of the mass is for the growth of clog as a porous medium. After 30 seconds, the second stage of clog growth (porous medium) becomes dominant. The period between 20 and 30 seconds is a transition period. All curves for different $\mathrm{N}$-factors show very similar trends, but in the transition period, some differences are observed. A larger $\mathrm{N}$-factor leads to a smaller mass contribution of the initial clog growth stage.

The aim of introducing the $\mathrm{N}$-factor is to reduce the calculation time without sacrificing calculation accuracy. Here, a deviation parameter, $\Delta$, is introduced to quantify the calculation accuracy:

$$
\Delta=\frac{M_{N}-M_{1}}{M_{1}} \times 100,
$$

where $M_{\mathrm{N}}$ stands for the total deposition mass when the $\mathrm{N}$-factor $=N$ and $M_{1}$ is the total deposition mass when the $\mathrm{N}$-factor $=1$ (the reference case: the calculation is most accurate). The variations of $\Delta$ with the $\mathrm{N}$-factor for cases with different particle size are shown in Figure 10(a). For the smallest particle size $(2 \mu \mathrm{m}), \Delta$ is negligible when $N<100$. However, for the largest particle size $(10 \mu \mathrm{m})$, when $N<10, \Delta$ is larger than 30 pct. This means that the dependency of the total mass deposition on the N-factor increases with an increase in particle size, indicating that the particle size should be taken into account as a factor influencing the $\Delta-N$ dependency. Hence, a dimensionless number, $\alpha$, is further defined. Actually, $\alpha$ is the ratio between the particle volumes considering the $\mathrm{N}$-factor and the volume of the cell:

$$
\alpha=\frac{N \times V_{\mathrm{p}}}{V_{\text {cell }}}
$$

where $V_{\mathrm{p}}$ and $V_{\text {cell }}$ are the volume of the particle and the volume of the computational cell, respectively. The parameter $\alpha$ can also be understood as a scaled (or dimensionless) N-factor. Coincidently, a linear correlation is obtained between $\Delta$ and $\alpha$, as shown in Figure 10(b). This indicates that numerical calculation accuracy increases with the decrease of $\alpha$. According 
to Figure $10(\mathrm{~b})$, if $10 \mathrm{pct}$ of $\Delta$ is accepted as a criterion for most engineering calculations, $\alpha$ should be smaller than 0.0002. In other words, to have a modeling result independent of the $\mathrm{N}$-factor, $\alpha$ should be chosen to be smaller than 0.0002 .

\section{DISCUSSION}

\section{A. Capabilities of the Clogging Model}

Clogging, based on the key mechanism of indigenous NMI particle deposition on the SEN wall, comprises some successive steps: (1) transport of particles to the wall, (2) attaching the particles to the wall, (3) growth of the clog, and (4) possible fragmentation (detachment) of particles. Different numerical models have been suggested for simulation of clogging using the Eulerian-Eulerian $^{[31-33]}$ or Eulerian-Lagrangian ${ }^{[34,35]}$ approach. In the study of SEN clogging during steel continuous casting, most numerical models deal with steps 1 and 2 of clogging, i.e., transport of particles by fluid flow toward the wall and deposition on the wall. ${ }^{[32,35,36]}$ The deposited particle is removed from the calculation and the effects of the deposited particle on the fluid flow are ignored. In some other works, the effects of clogging on the melt flow are investigated by changing the geometry manually. ${ }^{[17,37]}$ Obviously, the dynamic behavior of the buildup of the clog and its interaction with the flow are ignored. The most promising model to simulate SEN clogging, which can really cover transient two-way coupling between fluid flow and particle deposition, including steps 1 through 3 , is the recent transient clogging model developed by the current authors. ${ }^{[25]}$

To evaluate the calculation efficiency, a calculation of real SEN during steel continuous casting is performed (Figure 11). Characteristic dimensions are shown in Figure 11. To find the real number of solid particles entering into the SEN, a rough estimation is performed here. If the oxygen content of the steel melt in the tundish before entering SEN is around $30 \mathrm{ppm},{ }^{[38]}$ and if all of the oxygen reacts with dissolved aluminum in the steel melt to produce $\mathrm{Al}_{2} \mathrm{O}_{3}$ (the common NMI in the SEN), the concentration of $\mathrm{Al}_{2} \mathrm{O}_{3}$ in the steel melt would be $1.24 \times 10^{-4}$ vol pct. For the domain shown in the zoomed view in Figure 11(a) with total volume of $0.018 \mathrm{~m}^{3}, \sim 20$ billion particles with $d_{\mathrm{p}}=6 \mu \mathrm{m}$ should be calculated in the domain. Simulation of such a large number of particles is not feasible due to the huge calculation costs. Therefore, use of the number of representative particles ( $\mathrm{N}$-factor) to reduce the number of tracking particles is inevitable for the simulation of SEN clogging. A preliminary result of industry scale simulation of SEN clogging is depicted in Figure 11(b).

In the industry scale simulation, 30 minutes of the casting process are calculated. The steel mass flow rate is $58.25 \mathrm{~kg} / \mathrm{s}$. Alumina particles with diameter of $6 \mu \mathrm{m}$ are injected at a mass injection rate of $4.3 \times 10^{-9} \mathrm{~kg} / \mathrm{s}$. Here, the $\mathrm{N}$-factor is set to 1000 , corresponding to $\alpha=6 \times 10^{-5}$. The calculation time on 12 CPUs using the mentioned parameters is around 75 hours. Hence, by introducing the $\mathrm{N}$-factor, simulation for an industry process can be feasible. However, evaluation of the accuracy of the simulation needs accurate experimental data of SEN clogging, which is out of the scope of the current article.

In Figure 11(b), the clog front in the SEN is shown along with a zoomed picture of the thickness of the clog formed on the nozzle wall after 30 minutes. This figure shows that by using the clogging model, the critical regions of clogging during the casting process can be found. It should be noticed that clogging is a transient phenomenon and the critical position of clogging might be changed during the process due to the change in fluid flow by clogging.

\section{B. Calculation Accuracy and Efficiency}

The results of partially clogged cells illustrated in Figure 5 indicate that tetrahedron mesh does not work properly with the clog growth algorithm. As shown schematically in Figure 12, when an unstructured tetrahedron mesh is used, some cells may be filled sooner than the neighbor cells. For example, cell " $A$ " is fully filled before cell "B." Then, cell A is converted to fully clogged and its neighbor cells should be exposed to the particle deposition as partially clogged cells ("C" and "D"). The new partially clogged cell $\mathrm{C}$ may be fully filled sooner than cell $\mathrm{B}$, which is located in the downstream direction. Therefore, the old partially clogged cell B might be isolated and stay as a partially clogged cell forever. Owing to the fact that the clog is a network of the deposited particles, it is assumed that the clog acts as a filter. So, particles cannot go through the clog and are captured by partially clogged cells.

For the current version of the clogging model, tetrahedron mesh would lead to an unreliable result. With the improvement of the measurement of the particle distance from the clog in partially clogged cells, this issue would be solved. In cases with complex geometry, such as the SEN, where the creation of a mapped hexahedron mesh is too difficult, a combined mesh of tetrahedron cells in the bulk and wedge cells close to the walls can be used. According to the results of Figure 5, the clog growth algorithm works well with wedge mesh, such as hexahedron mesh, under no-flow conditions. By coupling the clog growth and the melt flow (Figure 6), deposition results of hexahedron mesh and wedge mesh look similar until $\sim 10$ seconds, when the clog front is close to the wedge-hexahedron border. It should be mentioned that clogging is a self-accelerating process; a small difference at the early stage of clogging can lead to a large difference at the later stage of clogging. As shown in Figure 6(c), the turbulence kinetic energy profile is not completely identical for hexahedron and wedge mesh. Note that the clog growth should be tracked only in the wedge cell region. From a CFD point of view, to have a more accurate fluid flow, the wedge mesh near the wall is also recommended instead of the tetrahedron mesh.

The results of Figures 7 and 8 indicate that the deposition mass until 20 seconds is almost identical in both distribution of the clog and total deposition mass for all values of the $\mathrm{N}$-factor. In addition, the results of 
Figures 8 and 9 show that after 20 seconds, when the second stage of the clog growth is dominant, the influence of the $\mathrm{N}$-factor on the deposition mass is observable. This issue happens for larger $\mathrm{N}$-factors earlier than for the smaller ones, which is understandable from the transition period shown in Figure 9. Therefore, the sensitivity of the clog growth to the $\mathrm{N}$-factor comes from the particle motion and deposition in the partially clogged cells, i.e., the second stage of the clog growth.

Assume that a certain mass of particles with the same size enters a partially clogged cell. If a larger $\mathrm{N}$-factor is chosen, fewer particles enter the partially clogged cell. In the severest situation, i.e., the largest $\mathrm{N}$-factor, only one particle would be in the partially clogged cell. If this particle reaches the clog front, the entire mass, which is equal to the mass of a single particle multiplied by $\mathrm{N}$, will be added to the clog. While, with smaller N-factor, several particles enter the cell. Some of them may reach the clog and the others may escape to the neighbor cells. That is, if the $\mathrm{N}$-factor is small, for a certain mass of the particles, there is more freedom for particles to escape from a partially clogged cell to the other neighbor cells. Therefore, the deposition mass in the partially clogged cell does not increase excessively at once. Hence, the smaller $\mathrm{N}$-factor results in less deviation in particle deposition than the larger $\mathrm{N}$-factor, as shown in Figure 8.

By changing the particle size, the effects of the $\mathrm{N}$-factor on the particle deposition change, as can be concluded from Figure 10. Therefore, a dimensionless number $\alpha$ is defined to select a reasonable $\mathrm{N}$-factor according to Figure 10(b). Although Figure 10(b) may not be valid for every simulation condition, $\alpha$ can be used to study the dependency of the deposition mass on this number. For example, for a process of industry scale, where simulation with the real number of particles is not feasible and a relatively large $\mathrm{N}$-factor should be selected, it is better to examine the particle deposition mass dependency on $\alpha$, as is always done for the mesh dependency during CFD calculations.

\section{Model Limitations and Outlook}

The current model has considered some important features of clogging, and it is proven to be applicable for calculation of clogging in the SEN of industry scale. However, some points are still missing. From the current knowledge about the possible clogging mechanisms (listed in Table I), it can be concluded that clogging is a typical multiphase, multiscale, and multiphysics phenomenon. It is multiphasic because liquid, solid particles, and gas bubbles are present. It is a multiscale issue because of the different length scales (NMI particle (micrometers) and SEN (cm)) and different time scales (particle Lagrangian time scale $(\mu \mathrm{m})$ and clogging duration (hours)). It is a multiphysics concern because different physics (fluid dynamics and solidification) play roles. Additionally, chemical reactions also may occur.

The current model considered mechanisms 1 and 5 (Table I), but mechanisms 2 through 4 were ignored or simplified. These mechanisms are related to chemistry and thermodynamics of the system. Most studies were made by postmortem analysis of inclusions or $\operatorname{clog}^{[13-15,30,39-43]}$ or through thermodynamic calculation of the involved phases (materials) related to clogging. ${ }^{[41,44-47]}$ These studies indicated that the clogging event was related to (or affected by) the thermodynamic or chemical properties of the involved materials, but no quantitative correlation between the clogging event and those thermodynamic or chemical properties was established. Therefore, further studies are required before an improved model can be developed by considering mechanisms 2 through 4.

Another limitation of the current model is due to the simplified NMI morphology and the ignorance of the NMIs' size distribution. Major NMIs during the plant operation were found to be globular in shape, but other possible shapes were also reported: cluster shape, dendrite shape, coral-shaped cluster, faceted particles, and even irregular plate..$^{27,30,48-50]}$ The model could be improved by modifying the drag force applied on the NMIs, so that the nonspherical particle (e.g., ellipsoid, fiber, or plate) can be taken into account. The model could also be extended for different NMI size groups. The size distribution of NMIs, which enter the SEN, can be estimated either from the analysis of melt samples taken from the tundish or from the numerical simulation by tracking the NMIs in the tundish.

The last step of clogging, i.e., fragmentation or detachment of clog material, is not included in the current clogging model. During the operation of continuous casting, the position of the stopper rod is dynamically adjusted to keep the steel melt rate in response to SEN clogging. ${ }^{[2]}$ The stopper rod rises when the clogging in the SEN occurs or the stopper rod has to be lowered if the detachment of clog material occurs. The fragmentation of clog is a source of new inclusions entering the mold region and may be captured by solidifying shell and lead to defects in the final product. ${ }^{[4]}$ A new model for the fragmentation or detachment demands further study on the as-clogged structure and its mechanical behavior.

\section{CONCLUSIONS}

A transient two-way coupling model, proposed for simulation of the clogging in SEN during continuous casting of steel, is evaluated referring to its sensitivity to the mesh type, calculation accuracy, and calculation efficiency.

The dependency of the model on mesh type is studied, because the geometry of SEN is complex and creation of unstructured tetrahedron mesh is more convenient than mapped hexahedron mesh.

1. Tetrahedron mesh does not work as a reliable mesh for clog growth.

2. Use of a combination of wedge mesh close to the wall, for tracking the clog growth, and tetrahedron mesh in the inner regions is recommended.

3. Wedge mesh behaves similarly to hexahedron mesh regarding clog growth. 
Due to the huge real number of particles in the SEN, all particles cannot be accounted for individually. Therefore, the $\mathrm{N}$-factor is necessarily introduced to improve the calculation efficiency.

1. The calculation results of particle deposition are not sensitive to the $\mathrm{N}$-factor at the initial clogging stage when particle deposition is taken into account by enhancement of the wall roughness.

2. During the late stage of clogging when particle deposition mostly leads to the growth of a porous medium, the N-factor would affect the model accuracy, depending on the particle size and mesh size. Therefore, a dimensionless number $\alpha=\left(N \times V_{\mathrm{p}}\right) /$ $V_{\text {cell }}$ is introduced to control the accuracy of the clogging calculation. If $\alpha<0.0002$, the calculation deviation is controlled within 10 pct.

Finally, simulation of a test case of clogging in the SEN during continuous casting shows that by selecting an appropriate $\mathrm{N}$-factor (1000, corresponding to $\left.\alpha=6 \times 10^{-5}\right)$, the calculation time would be reduced to a reasonable time ( $\sim 5$ hours $)$, i.e., the calculation efficiency would be significantly improved.

\section{ACKNOWLEDGMENTS}

Open access funding provided by Montanuniversität Leoben. The authors gratefully acknowledge the funding support of K1-MET, metallurgical competence center. The research program of the K1-MET competence center is supported by the Competence Center for Excellent Technologies (COMET), the Austrian program for competence centers. COMET is funded by the Federal Ministry for Transport, Innovation and Technology, the Federal Ministry for Science, Research and Economy, the provinces of Upper Austria, Tyrol, and Styria as well as the Styrian Business Promotion Agency (SFG).

\section{OPEN ACCESS}

This article is distributed under the terms of the Creative Commons Attribution 4.0 International License (http://creativecommons.org/licenses/by/4.0/), which permits unrestricted use, distribution, and reproduction in any medium, provided you give appropriate credit to the original author(s) and the source, provide a link to the Creative Commons license, and indicate if changes were made.

\section{REFERENCES}

1. B.G. Thomas and H. Bai: Steelmaking Conf. Proc., 2001, vol. 84 , pp. $895-912$.

2. L. Zhang and B.G. Thomas: Metall. Mater. Trans. B, 2006, vol. 37B, pp. 733-61

3. S. Basu, S.K. Choudhary, and N.U. Girase: ISIJ Int., 2004, vol. 44 , pp. 1653-60.
4. N. Kojola, S. Ekerot, M. Andersson, and P.G. Jönsson: Ironmak. Steelmak., 2011, vol. 38, pp. 1-11.

5. N. Kojola, S. Ekerot, and P. Jönsson: Ironmak. Steelmak., 2011, vol. 38 , pp. $81-89$.

6. E. Roos, A. Karasev, and P.G. Jönsson: Steel Res. Int., 2015, vol. 86, pp. 1279-88.

7. S.N. Singh: Metall. Trans., 1974, vol. 5, pp. 2165-78.

8. Y. Vermeulen, B. Coletti, B. Blanpain, P. Wollants, and J. Vleugels: ISIJ Int., 2002, vol. 42, pp. 1234-40.

9. K. Sasai and Y. Mizukami: ISIJ Int., 1994, vol. 34, pp. 802-09.

10. K. Sasai and Y. Mizukami: ISIJ Int., 1995, vol. 35, pp. 26-33.

11. V. Brabie: ISIJ Int., 1996, vol. 36, pp. S109-12.

12. Y. Fukuda, Y. Ueshima, and S. Mizoguchi: ISIJ Int., 1992, vol. 32, pp. 164-68.

13. R.B. Tuttle, J.D. Smith, and K.D. Peaslee: Metall. Mater. Trans. $B, 2007$, vol. 38B, pp. 101-08.

14. R.B. Tuttle, J.D. Smith, and K.D. Peaslee: Metall. Mater. Trans. B, 2005, vol. 36B, pp. 885-92.

15. F. Tehovnik, J. Burja, B. Arh, and M. Knap: Metalurgija, 2015, vol. 54, pp. 371-74.

16. P.M. Benson, Q.K. Robinson, and C. Dumazeau: Unitecr'93 Congr. Refractories for the New World Economy, Proc. Conf. Sao Paulo, 1993, vol. 31 .

17. H. Bai and B.G. Thomas: Metall. Mater. Trans. B, 2001, vol. 32B, pp. 707-22.

18. M. Suzuki, Y. Yamaoka, N. Kubo, and M. Suzuki: ISIJ Int., 2002, vol. 42, pp. 248-56.

19. G.C. Duderstadt, R.K. Iyengar, and J.M. Matesa: JOM, 1968, vol. 20 , pp. $89-94$.

20. J.W. Farrell and D.C. Hilty: Electric Furn. Proc., 1971, vol. 29, pp. 31-46.

21. S. Rödl, H. Schuster, S. Ekerot, G. Xia, N. Veneri, F. Ferro, S. Baragiola, P. Rossi, S. Fera, V. Colla et al.: New Strategies for Clogging Prevention for Improved Productivity and Steel Quality, 2008.

22. K.G. Rackers and B.G. Thomas: 78th Steelmaking Conf. Proc., 1995, vol. 78, pp. 723-34.

23. J. Szekely and S.T. DiNovo: Metall. Trans., 1974, vol. 5, pp. 74754.

24. H. Barati, M. Wu, A. Kharicha, and A. Ludwig: in Solidification and Gravity VII, G.K.A. Roósz, Z. Veres, and M. Svéda, eds., Hungarian Academy of Sciences, Miskolc-Lillafüred, 2018, pp. 144-49.

25. H. Barati, M. Wu, A. Kharicha, and A. Ludwig: Powder Technol., 2018, vol. 329, pp. 181-98.

26. M. Guingo and J.-P. Minier: Phys. Fluids, 2008, vol. 20, p. 053303.

27. D. Janis, A. Karasev, R. Inoue, and P.G. Jönsson: Steel Res. Int., 2015, vol. 86, pp. 1271-78.

28. F.R. Menter: AIAA J., 1994, vol. 32, pp. 1598-1605.

29. F.R. Menter, M. Kuntz, and R. Langtry: Turbul. Heat Mass Transfer, 2003, vol. 4, pp. 625-32.

30. Z. Deng, M. Zhu, Y. Zhou, and D. Sichen: Metall. Mater. Trans. $B$, 2016, vol. 47B, pp. 2015-25.

31. D. Eskin, J. Ratulowski, and K. Akbarzadeh: Chem. Eng. Sci., 2011, vol. 66, pp. 4561-72.

32. P. Ni, L.T.I. Jonsson, M. Ersson, and P.G. Jönsson: Metall. Mater. Trans. B, 2014, vol. 45B, pp. 2414-24.

33. P. Ni, L.T.I. Jonsson, M. Ersson, and P.G. Jönsson: Int. J. Multiphase Flow, 2014, vol. 62, pp. 152-60.

34. C. Caruyer, J.-P. Minier, M. Guingo, and C. Henry: Advances in Hydroinformatics, Springer, New York, 2016, pp. 597-612.

35. M. Long, X. Zuo, L. Zhang, and D. Chen: ISIJ Int., 2010, vol. 50, pp. 712-20.

36. M. Mohammadi-Ghaleni, M. Asle-Zaeem, J.D. Smith, and R. O'Malley: Metall. Mater. Trans. B, 2016, vol. 47B, pp. 3384-93.

37. L. Zhang, Y. Wang, and X. Zuo: Metall. Mater. Trans. B, 2008, vol. 39B, pp. 534-50.

38. A. Jungreithmeier, E. Pissenberger, K. Burgstaller, and J. Mortl: Iron \& Steel Society International Technology Conference and Exposition, 2003, pp. 227-40.

39. J.K.S. Svensson, A. Memarpour, V. Brabie, and P.G. Jönsson: Ironmak. Steelmak., 2017, vol. 44, pp. 108-16.

40. M. Li, H. Matsuura, and F. Tsukihashi: Mater. Charact., 2018, vol. 136, pp. 358-66. 
41. E. Roos, A. Karasev, and P.G. Jönsson: Steel Res. Int., 2014, vol. 85, pp. 1410-17.

42. X. Yin, Y. Yang, D. Li, Y. Sun, X. Deng, M. Barati, and A. McLean: Ironmak. Steelmak., 2017, vol. 44, pp. 140-51.

43. Z. Deng, M. Zhu, B. Zhong, and D. Sichen: Metall. Mater. Trans. $B, 2014$, vol. 54B, pp. 2813-20.

44. Y.-B. Kang and J.-H. Lee: ISIJ Int., 2017, vol. 57, pp. 1665-67.

45. J.-H. Lee, S.-K. Kim, M.-H. Kang, and Y.-B. Kang: BHM Berg Hüttenmänn. Monatshefte, 2018, vol. 163, pp. 18-22.

46. I.-H. Jung, G. Eriksson, P. Wu, and A. Pelton: ISIJ Int., 2009, vol. 49, pp. 1290-97.
47. I.-H. Jung: Calphad, 2010, vol. 34, pp. 332-62.

48. B.G. Thomas, Q. Yuan, S. Mahmood, R. Liu, and R. Chaudhary: Metall. Mater. Trans. B, 2014, vol. 45B, pp. 22-35.

49. L. Zhang and W. Pluschkell: Ironmak. Steelmak., 2003, vol. 30, pp. 106-10.

50. R. Dekkers, B. Blanpain, P. Wollants, F. Haers, B. Gommers, and C. Vercruyssen: Steel Res. Int., 2003, vol. 74, pp. 351-55.

Publisher's Note Springer Nature remains neutral with regard to jurisdictional claims in published maps and institutional affiliations. 